\title{
The Origin of Calligraphy of Jian Theory and Chinese Painting
}

\author{
Yaping Yang \\ Baoshan University, Baoshan Yunnan 678000 China
}

Keywords: calligraphy, Chinese painting, origin.

\begin{abstract}
Calligraphy is traditional and ancient Chinese culture, and it is mutually affected and influenced by Chinese painting during the thousand-year development and inheritance. "The same origin of calligraphy and painting" means the close relationship of this sister arts. This paper made an attempt to discuss the same origin of calligraphy and painting and their respective distinctive aesthetic charm.
\end{abstract}

\section{Introduction}

The traditional Chinese painting and calligraphy art has a long history. After going through thousands of years of the ups and downs, it gradually formed a distinctive national style and personality of art form, and these two kinds of art especially since the Yuan, Ming have permeated and influenced each other, while western watercolor paintings and oil paintings, obviously have no essential connection with their national characters. Besides, it is not difficult to find that Chinese calligraphy and painting art have the same aesthetic idea, which is to say that the basis of their foundation is the same. Therefore, from the perspective of world cultural history, it is typical of China to connect writing with painting. From the history of Chinese calligraphy and painting, there are countless examples of both painter and calligrapher. However, they are independent of each other, and as different art categories, they have their own historical periods and laws. So where is the origin of the painting and calligraphy, where is the source, and where is it different?

\section{Painting and calligraphy have a common origin.}

\subsection{The selection of tools and materials is homologous.}

The tools used in Chinese calligraphy and painting are based on the basic material of the brush, ink, Xuan paper (or silk) and water in the process of creation. In particular, the invention and use of the brush and Xuan paper are unique to our country. On the one hand, the unique materials will produce the corresponding creation methods. On the other hand, the unique creation methods will eventually lead to the uniqueness of the works style. The biggest characteristic of the brush is soft, which is used to express rigid or soft line. The Chinese have found various methods in the long practice, of which "yong" the eight method is a typical example. And these methods depend on the effect of Xuan paper to produce a series of rich effects such as dry wet, shade, degree of thickness, square and cleverness. As the famous calligrapher Cai Yong in the Eastern Han Dynasty said, "it is strange to have a soft pen." The brush can be said to be "Chinese characteristics" -- simplicity -- which is consistent with the Chinese Taoist thought "life two, two life three, three living things." To create the most complex images with the simplest tools is unique to our art. The tools used in western painting are like the utensils used for eating, while the Chinese are just using bamboo chopsticks.

Imagine what it would be like to give up our existing brushes and use other tools to create Chinese paintings. For example, if we use the flat combination brush pen for oil painting and paint to create Chinese painting, what will be the result? Chinese painting without writing brush, ink and paper, is likely to be a picture, but it can't be a picture with Chinese characteristic (of course referring to the ink is another matter, as its essential guiding ideology is still Chinese.) From the cultural origin of China, whether it is half - slope type of human face fish - colored pottery basin in a new Stone Age, or Yin ruins oracle, they use the same tool - the brush pen. Today, in the course of thousands of years of development, the tools used in calligraphy and painting have not been mutated. Besides, Chinese painting is actually "two primary colors" -- black, white, and it's enough to possess the most basic 
black ink, white paper, while western painting is "three primary colors" -- red, yellow and blue, and some scholars say that Chinese painting is "five primary colors" -- black, white, red, yellow and blue. It seems that black and white are indispensable.

\subsection{The use of pen and the ink are the same.}

Chinese calligraphy and painting emphasize "the brush method", which is nothing but the correct method of taking and using the pen. The Elegance of the Bamboo and Spring written by Guo Xi who lived in the Northern Song Dynasty records that : "if one cannot manipulate the pen and the ink, how can he obtain the pleasure of it? This is also not difficult, close to calligraphy. Therefore, it is said that the Wang Xizhi likes goose. He is meant to be used for the transfer of a person's pen to the wrist to make a letter, which is the same as the pen. So the people who is adept at calligraphy is also good at painting, and the gaiter of his writhing is not delayed. (1)" This emphasizes the origin of calligraphy and painting. Mr. Huang Binhong summed up the rules of Chinese painting as: "the pen should be flat, like the drawing sand.The pen must be round, like the hairpin; To use a pen like a leak in the house; Using a pen as heavy as a mountain." It is made of being flat, round, light, heavy and variable."Using a pen to make words like 'taper painting sand'. Or it will be frivolous. The round words are like "the flowers of the flowers". Or it will be inflexible. Save as a 'leak,' not to be left unreserved.Words like 'high mountain falling stone', not heavy wind blowing leaves, full of sloppy paper.Change as the front has eight sides, the word has eight laws, the invariant is horizontal draw like 'the cloth calculate', straight draw like 'cloth chess' "(2). This is a fine summary of the penmanship. In the white trace, the traditional "18 strokes", its form is actually determined by the pen. One of the six laws written by Xie He living in Southern Qi Dynasty has "bone law pen", and also emphasizes the importance of pen to painting. It can be seen that the correct pen method is of great significance to calligraphy and painting.

Chinese painting with pen and ink as the main modeling means, "the ink is main, color is the auxiliary", "ink consists of five colors" namely focus, thick, heavy, light, clear, with different thick layers to enrich the picture. The thick ink is deep, the light ink is flowing, these two inks can not only unify the screen, but also enrich the picture. This characteristic has affinity with calligraphy. A successful calligraphy work, not only depends on the point painting, the combination, the rules, but the ink color of the thickness, dry wet, the weight also has the same important status. If the ink has been wet, with the dry ash flat and the line being bulky, the words written will have no bones. On the other hand, if the ink is too thick, the line will harden and there will be no flesh. As Ouyang Xun once said in The Eight Tips: "the color of ink is the color of pain.Fat is blunt, thin is bone, do not hurt to be weak, do not have to be angry (3). The blood and meat of the word are produced by the phase between the ink and the ink, and the bone and meat should be matched to the ideal effect of "reasonable emotion on the paper with variation".It is only in calligraphy creation that the thick, weak, smooth and dry use of ink can achieve perfection, air, god, bone, flesh and blood.

The brushwork and the ink are the essence of Chinese calligraphy and painting art, and different pens and ink colors will make the paintings more interesting and rhyming.If one piece lacks both, it is not a traditional Chinese painting.

\subsection{Aesthetic thoughts are homologous}

Chinese calligraphy and painting is an important part of traditional Chinese culture, which contains rich and deep cultural connotations. Although they are the same as visual art, they belong to two different types. In the evolution of long history, they follow the principle of interactivity and independent development. Yet the aesthetic value of painting and calligraphy art involved in works of artistic conception, emphasizes "writing god in form, writing in the form of writing", and are compensated and not yet smart, it is thick and not thin, elegant and not yet vulgar, expounded yet not yet exposed...That is to say, both forms share common Chinese values. When we look at a painting or a calligraphy work, we often don't focus on local, but the first view of the whole momentum spirits, overall the handing down, and then note writing style, then to observe the nexus of contracts of words or drawing level. A painting in the calligraphy works, a little bit of the national painting. The famous painter, Mr. Chen Zizhuang, said, "if a picture can be divided and the view is calligraphy, and the view is a painting, it is a good work, but it is not easy to achieve. "Produced by ink organic tissue at 
the same time, momentum, rhythm, rhyme, etc, create the physique flesh and blood, strong vitality of artistic style and image, to achieve the true, the good and the beautiful art realm. It not only reveals the creator of life environment, knowledge, accomplishment, personality characteristics and skills for using pen and ink, which works to affect audience, leading people to continuously pursue the true, the good and beauty.

Chinese calligraphy and painting (line) modeling, the use of the dots (lines) is beyond the requirement of shaping the body, becoming the means to express the ideas, thoughts and emotions of the author.There is no natural attachment between the dots (lines) and the objects (pictured).As Zheng Banqiao said, when he began to draw bamboo in the morning, the bamboo in his chest was not the bamboo in his eyes, and the bamboo in his hand was not the bamboo in his chest.Both calligraphy and painting originated from the natural and higher art form. There is no line in real life, which is the result of high generalization and refinement of life. The rhythm, the rhyme, the dynamics, the momentum, the beauty of interest are all derived from nature, but also through the ingenuity of the creator.

\subsection{Stylized application of the same origin}

All kinds of art categories, whether calligraphy, painting, dance, music, opera, in traditional teaching, one of the characteristics of teaching techniques is to use stylized methods. The program originated from the life, is the objective phenomenon in the life gradually turning into the artistic style that holds the specific summary method.This is related to the Chinese way of expression, which was mainly made by observing and then writing in a silent way, rather than in the western tradition.In this process, objective objects have been flexibly handled by the author, such as trade-off, exaggeration, deformation, refinement, and generalization, presenting a marked characteristic of symbolization. Such as the description of the characters, the brush strokes of the rocks, the rules of the buildings, the various points of the leaves, the various shapes of the flowers and birds, and the ways of the back... All are the results of the previous observation of life and reproduction of life.Compilation of "Mustard Seed Garden Painting" at the beginning of the Qing dynasty from landscapes, figures, flowers and birds painting reflects the predecessors' pen, writing techniques, shape and composition of a picture while Mustard Seed Garden Painting, lack of sketch method, the stylized technique provides a powerful model for beginners. Outstanding painter once master the basic method and then go into the thick of life, to create their own a set of programs (or languages), so, the generations of the cycle, is blended into the traditional river.

Chinese calligraphy has a word "forever" in the traditional teaching method of eight, through the basic stippling - point of Chinese characters, points, horizontal, vertical, skimming, cutting, lifting, hook, folding and various image. And once the beginners master these skills, they tend to look natural, even into the thick of life, the ancient Chinese outstanding calligrapher observe "aunt sun sword", "summer cloud mutation", "wall demolition" and so on, and then put these things into fresh technique, traditional handwriting by dotted form on the change and adjustment, to produce various image, which is of different styles of calligraphy. In the seal script, official script, zhenshu, xingshu and cursive script, the writing of basic strokes is different, but the following rules are consistent with stylized writing methods.

\subsection{Printing of the same origin}

A picture of the complete books, includes drawing, knot words, promoting qi, arranging the blank relationship between lines and words, inscription, sealing, and mounting arrangement with the surrounding environment coordination, etc. Although inscription and sealing occupy less space position, they are an integral part of the whole.It involves a variety of different forms, such as single, double, long and poor, which involves the whole issue of weight and balance.Closely combined with inscription is the use of seals, due to being in a thorough contrast, and a bit red, not only has a certain decorative beauty, but has the effect of breaking the rigid and adjusting composition artistically.

The famous painting works in the Tang Dynasty and Five Dynasties just explain the author to make is convenient for the viewers in the same or late times to understand, so mistake is inevitable. Until the Song and Yuan Dynasties, painting was rather prosperous and the inscriptions in the drawing were more common, for instance, the paintings of Zhao Mengfu and his son and the four great painter 
in Yuan Dynasty had inscriptions and seals, including name seal and "free seal" of calligraphy and painting. The further development and improvement of inscriptions and seals not only strengthened the meaning of drawing but enhanced the aesthetics of picture form. Ever since the Yuan, Ming and Qing Dynasties, nearly every painting cannot separate from the calligraphy seal, and the perfect combination of calligraphy and painting makes Chinese painting, such a national traditional art, increasingly perfect.

\section{Calligraphy and painting have their own schools and distinctive artistic charm}

The basic characteristic of calligraphy is abstraction, including the meaning of two aspects: firstly, Chinese character is abstract and symbolic through thousand-year evolution. Secondly, the figurative elements of calligraphy is point, line and face, which are the high abstraction in the visual elements. These abstractions have immersed into the blood vessel of the descendants of the Chinese Nation in the thousand-year inheritance, and even a little child can understand Chinese character. It cannot take effect that letting the western accept these without the soil, but it will be easier to let them view a Chinese painting. The other characteristic of calligraphy is expression, closer to music. The reason is that the process of calligraphy is time sequence, one by one, and painting is less prominent than calligraphy or music. And the instant emotion of the author can be fully expressed in this process. As Sun Guoting of Tang Dynasty said that "Emotion is expressed on the appearance and corresponding to the nature. It cannot lose the emotion, or else, the essence will not exist!" (4) Calligraphy is the expression and reveal of emotion, the combination with nature, so once it detaches the corresponding emotion, the essence beauty will lose. There is an increasingly promoting process from the quality to literature during the process from its generation to the formation in various chirography such as seal, clerical, regular, running and cursive script. Namely, any calligraphy has its own distinctive characteristic. Calligraphy is based on characters and makes writing brushes the writing instrument, and it is equipped with four-dimension abstract symbol art, which shows the "unity of opposites" of various things. This principal rule also reflects the spirit, temperament, knowledge and quality of the body of people.

The most prominent thing of Chinese painting from calligraphy is also the "figure". It can be said that this is the function of painting from the Qin and Han Dynasty. Whether Zhou Fang, Han Gan, Li Tang and Zhao Ji in the Tang and Song Dynasties or the anonymous painters who painted the Dunhuang frescoes, they make the symbol as the standard and serve society, politics and religion. For the accurate figure, they are basically exercising for a few hours from the childhood just as the present art high school graduates making the strict model exercise. Not until the middle part of Ming Dynasty, the practice of Xu Wei and Dong Qichang, calligraphy is included to the painting, so painting truly entered the times of expression and ink, but symbol still is the distinctive characteristic of painting.

We can draw the conclusion from the relationship between calligraphy and Chinese painting that they have the same origin but different flows, and they have many common places on the pen, ink and paper. Those people who are good at calligraphy also can paint and vice versa. Although the method is a little different, the principle is connected. In the Famous Ancient Record - Six Tips on Painting, Zhang Yanyuan pointed out that "The similarity of things must be on the appearance, while the similarity of shape must rely on the backbone that is based on the concept and manifested by the pen, so those painters are likely to do well in calligraphy"(5). And that "those painters are likely to do well in calligraphy" highlights that painters are supposed to be good at calligraphy.

\section{Annotations}

(1)Zhou Jiyin, Chinese Painting Theory, Jiangsu Fine Arts Publishing House, July, 2005, P537.

(2)Huang Binhong, Notes of Huang Binhong on Literature and Art, Henan Arts Press, September, 2007, P54.

(3)Huang Jian, The Anthology of Ancient Chinese Calligraphy, Shanghai Book and Painting Press, October, 1979, P98. 
(4)Huang Jian, The Anthology of Ancient Chinese Calligraphy, Shanghai Book and Painting Press, October, 1979, P128-129.

(5)Huang Binhong, Notes of Huang Binhong on Literature and Art, Henan Arts Press, September, 2007, P45.

\section{Acknowledgments}

Fund project: Special Training Program for Outstanding Young Teachers in Colleges and Universities of Education Department in Yunnan Province Yunjiaogao【2015】 No. 92 Fund Project

\section{References}

[1] Zong Baihua, Aesthetics Walk, Shanghai People's Publishing House, June, 1981.

[2] Dong Bingcong, Calligraphy and Painting, Gezhi Press, December, 1999.

[3] Wang Bomin, The General History of Chinese Painting, Beijing: Sanlian Bookstore Press, December, 2000.

[4] Yang Renkai, Chinese Painting, Shanghai Chinese Classics Publishing House, January, 2005.

[5] Zhou Jiyin, Chinese Painting Theory, Jiangsu Fine Arts Publishing House, July, 2005. 